\title{
119. Effect of Neurohypophyseal Hormones on Thyroxine-Induced Resorption of Tadpole Tail in vitro
}

\author{
By Syoichi Iwamuro, Yuko Yamaguchi, Tetsuya Kobayashi, \\ and Sakaé KiKUYAMA \\ Department of Biology, School of Education, Waseda University, \\ Shinjuku-ku, Tokyo 160 \\ (Communicated by Kiyoshi TAKewaki, M. J. A., Nov. 12, 1985)
}

According to Platt and his coworkers, injections of oxytocin (OT), lysinevasopressin (LVP) or arginine vasotocin (AVT) into Ambystoma tigrinum larvae,11,12) invariably caused an acceleration of gill resorption, whereas tail fin resorption was promoted only by injections of OT, the other hormones being without effects. Since it is well established that amphibian neurohypophyseal hormones are mesotocin (MT) and AVT,1),3),9) the present study was undertaken to see whether either of these two hormones has any effect on thyroxin $\left(T_{4}\right)$ induced shrinkage of tail tissue of toad tadpoles in vitro.

Materials and methods. Premetamorphic tadpoles of Bufo japonicus formosus were used. A $4 \mathrm{~mm}$-long segment excised from tail of each tadpole at the region about $10 \mathrm{~mm}$ apart from its base was cultured at $22^{\circ} \mathrm{C}$ in a well of the culture plate ( $16 \mathrm{~mm}$ in diameter, Corning) containing $2 \mathrm{ml}$ of Gey's medium diluted to adjust to amphibians $\left.{ }^{5}\right)(\mathrm{pH} 7.2)$ in a sterile condition. The medium was supplemented with $\mathrm{T}_{4}\left(2.5 \times 10^{-7} \mathrm{M}\right.$; Sigma $)$ and/or either MT $(20-200 \mathrm{ng} / \mathrm{ml}$; Bachem) or AVT $(2-200 \mathrm{ng} / \mathrm{ml}$; Cambridge Research Biochemical). Throughout the experimental period, daily profiles of each tail piece were drawn on drawing paper using a microprojector (Bellco Glass Inc., JPV-194) and the areas were measured with an automatic area meter (Hayashi Denko). The extent of tail resorption was estimated as the percentage change from the initial area.

Results. Segments of tail cultured in the medium containing $\mathrm{T}_{4}$ began to shrink on the day following the initiation of culture and after 3 days, they decreased to about $40 \%$ of the initial size (Figs. 1 and 2). Acceleration by MT $(20-200 \mathrm{ng} / \mathrm{ml})$ of $\mathrm{T}_{4}$-induced shrinkage was clear-cut 2 days after the start of culture (Fig. 1). In the absence of $\mathrm{T}_{4}, \mathrm{MT}$ did not call forth any visible change in segments. By contrast, AVT $(2-200 \mathrm{ng} / \mathrm{ml})$ was without effect on tail segments, regardless of the presence or absence of $\mathrm{T}_{4}$ (Fig. 2). In the latter case, only representative data (cuiture in $20 \mathrm{ng} / \mathrm{ml} \mathrm{AVT}$ ) are shown.

Discussion. Platt and LiClause $^{2)}$ have reported that OT administration brings about an acceleration of $\mathrm{T}_{4}$-induced resorption of tail fin in larval $\mathrm{Am}$ bystoma tigrinum and abolishes the anti-metamorphic action of prolactin on the fin. According to these workers, OT has a dehydrating effect on the explanted tail tissue.12) Since $\mathrm{T}_{4}$ induces a loss of water and sodium from larval tiger salamander tissue and prolactin promotes their retention, ${ }^{10)}$ they concluded that OT accelerates $\mathrm{T}_{4}$-induced metamorphosis and block anti-metamorphic action of prolactin through its diuretic effect on the tissue. 


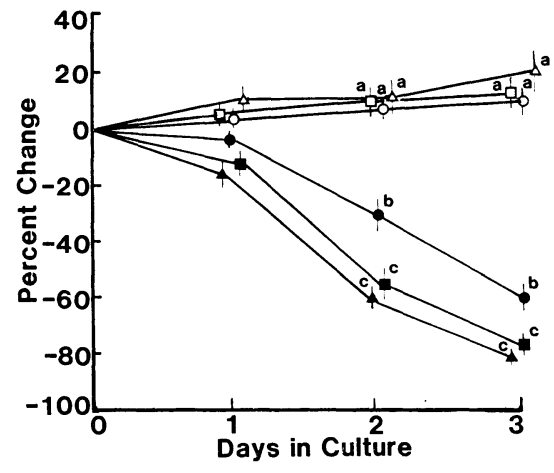

Fig. 1

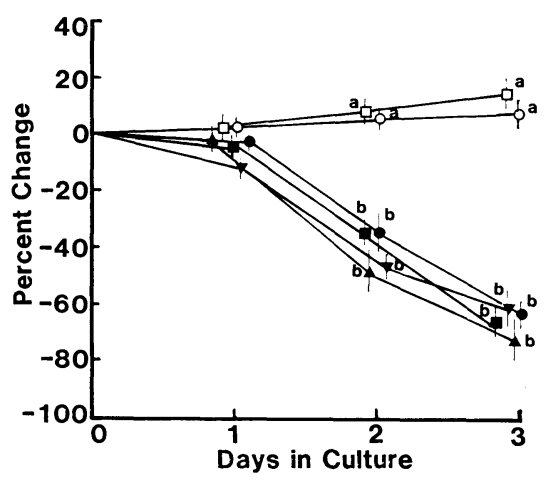

Fig. 2

Figs. 1 and 2. 1: Effect of MT on $\mathrm{T}_{4}$-induced resorption of tail segment of toad tadpoles. Tail segments were maintained in medium containing $2.5 \times 10^{-7} \mathrm{M} \mathrm{T}_{4}$ $(--), \mathrm{T}_{4}+20 \mathrm{ng} / \mathrm{ml} \mathrm{MT} \mathrm{(- \square -),} \mathrm{T}_{4}+200 \mathrm{ng} / \mathrm{ml} \mathrm{MT}(-\boldsymbol{\Delta}-), 20 \mathrm{ng} / \mathrm{ml} \mathrm{MT}$ $(-\square-), 200 \mathrm{ng} / \mathrm{ml} \mathrm{MT}(-\triangle-)$, or in control medium (-○-). Each point and vertical line represent the mean of 6-8 determinations and standard error of the mean, respectively. Means with the same superscript do not differ significantly from each other at $\mathrm{P}<0.05$ (Student's $t$-test). 2 : Effect of AVT on $\mathrm{T}_{4}$ induced resorption of tail segments of toad tadpoles. Tail segments were cultured in medium containing $2.5 \times 10^{-\tau} \mathrm{T}_{4}(-\bullet-), \mathrm{T}_{4}+2 \mathrm{ng} / \mathrm{ml} \mathrm{AVT}(-\nabla-), \mathrm{T}_{4}+$ $20 \mathrm{ng} / \mathrm{ml} \mathrm{AVT} \mathrm{(--),} \mathrm{T}_{4}+200 \mathrm{ng} / \mathrm{ml}$ AVT (-A-), $20 \mathrm{ng} / \mathrm{AVT}(-\square-)$, or in control medium (-O-). Each point and vertical line represent the mean of 6 determinations and standard error of the mean, respectively. Means with the same superscript do not differ significantly from each other at $\mathrm{P}<0.05$ (Student's $t$-test).

The present experiment revealed that MT, one of the two amphibian neurohypophyseal hormones, was effective in accelerating $\mathrm{T}_{4}$-induced shrinkage of tail segments of toad tadpoles by acting directly on the tissue. At present, however, the mechanism of action of MT on the tail is not clear, although it is known that MT has diuretic effect on many amphibians..$^{4), 8)}$

AVT, another neurohypophyseal hormone of amphibians, was found to be ineffective in accelerating $\mathrm{T}_{4}$-induced shrinkage of tail segments. Platt and Hill have also reported that administration of AVT to tiger salamander larvae had no effect on tail fin, although AVT interfered with the inhibition of tail fin regression by prolactin. ${ }^{11)}$

Recently, evidence has accumulated for the involvement of hormones other than thyroid hormone, i.e. prolactin and adrenal steroids in the process of amphibian metamorphosis. ${ }^{2)(6), 13)}$ The findings reported here indicate that MT accelerates $\mathrm{T}_{4}$-induced shrinkage of tadpole tail in vitro. However, concentrations of MT in the frog circulation as measured by radioimmunoassay are reported to be $2-20 \mathrm{pg} / \mathrm{ml}$, which are much lower than those used in the present experiment. ${ }^{7)}$ Further studies are needed to determine whether the neurohypophyseal hormone plays a physiological role in regulating amphibian metamorphosis.

Acknowledgments. The authors wish to express their cordial thanks to Professor Emeritus K. Takewaki of the University of Tokyo, M. J. A., for reading the manuscript. This work was supported by Grants-in-Aid from the Ministry of Education, Science and Culture of Japan and a research grant from Waseda University to $\mathrm{S}$. $\mathrm{K}$. 


\section{References}

1) Acher, R. et al. (1964): Gen. Comp. Endocrinol., 4, 596-601.

2) Dodd, M. H. I., and J. M. Dodd (1976) : Physiology of Amphibia (ed. Lofts, B.). vol. 3, Academic Press, New York, pp. 467-599.

3) Follet, B. R., and H. Heller (1964) : J. Physiol., 172, 92-106.

4) Galli-Gallardo, S. M., P. K. T. Pang, and C. Oguro (1979): Gen. Comp. Endocrinol., 37, 134-136.

5) Kikuyama, S., and I. Yasumasu (1972): Endocrinol. Japon., 19, 549-555.

6) Kikuyama et al. (1985): Current Trends in Comparative Endocrinology (eds. Lofts, B., and W. N. Holmes). Hong Kong Univ. Press, Hong Kong, pp. 535-537.

7) Nouwen, E. J., and E. R. Kühn (1983) : Gen. Comp. Endocrinol., 50, 242-251.

8) Pang, P. K. T., and W. H. Sawyer (1978): Amer. J. Physiol., 235, F 151-F 155.

9) Pickering, B. T., and H. Heller (1959): Nature, 184, 1463-1464

10) Platt, J. E., and M. A. Christopher (1977) : Gen. Comp. Endocrinol., 31, 243-248.

11) Platt, J. E., and P. L. Hill (1982) : ibid., 48, 355-361.

12) Platt, J. E., and M. L. LiCause (1980): ibid., 41, 84-91.

13) White, B. A., and C. H. Nicoll (1981): Metamorphosis (eds. Gilbert, L. I., and E. Frieden). Plenum Press, New York, pp. 363-396. 